\title{
Gerência de serviços de saúde: competências desenvolvidas e dificuldades encontradas na atenção básica
}

\author{
$M$ anagement of health services: developed competencies \\ and difficulties found in basic attention
}

Léia Cristiane Löeblein Fernandes ${ }^{1}$

Rebel Zambrano $\mathrm{M}$ achado $^{2}$

Geovana Oliveira Anschau ${ }^{3}$

\footnotetext{
${ }^{1}$ Secretaria M unicipal de Saúdede Caxias do Sul. Rua $M$ arechal Floriano 420, Bairro Centro. 95020-372 Caxias do Sul RS. leia-cris@hotmail.com ${ }^{2}$ Coordenação do Curso de Administração de Sistemas eServiços de Saúde, Universidade Estadual do Rio Grandedo Sul.

${ }^{3}$ H ospital Santo Ângelo.
}

\begin{abstract}
The objective of this article is to know the profile and check the competencies, management attributions and abilities in the level of structure of Basic Attention; to identify the difficulties and easiness in relation to their attributions and manage ment of people. The research is a subject of study. A semi-structured and a scale of Likert were used as the guide of research that was applied to the management of the basic units of health of Caxias do Sul, Rio Grande do Sul State, in November of 2006. It was evidenced that all managers have management skills that include communication, organization of tasks, planning of actions and negotiation. However, some described that the difficulty for the accomplishment of their attributions would be not having specific graduation in management. The problems in higher evidence were related to the bureaucracy excess, the overload of activities, the small physical area, the difficulties in manipulating and working with equipment as well as managing people. It has been noticed that there is a great need of computerizing the public system and enable professionals to work in programs, in order to accomplish the new assistance model and to recognize situations of social vulnerability and in health.

Key words M anagement, Family health, Municipal system of health
\end{abstract}

Resumo Este estudo tem como objetivo conhecer o perfil e verificar as competências, atribuições e habilidades gerenciais, no nível de estrutura da atenção básica; identificar as dificuldades e facilidades em relação às suas atribuições e em relação à gestão depessoas. A pesquisa éum estudo decaso. 0 instrumento de coleta utilizado foi um questionário semiestruturado e uma escala de Likert, aplicada às gerências das unidades bási cas de saúde de Caxias do Sul (RS), no mês de novembro de 2006. Constatouse que todas as gerentes possuem habilidades gerenciais, que abrangem a comunicação, a organização de tarefas, o planejamento de ações e a negociação. Entretanto, algumas descreveram como dificuldade para a realização de suas atribui ções não ter formação específica em gerenciamento. O s problemas com maior evidência se relacionaram ao excesso de burocracia, à sobrecarga de ati vidades, à pequena área física, às dificuldades em manipular etrabalhar com equipamentos eà gestão de pessoas. N ota-se que há grande necessi dade de informatizar a rede pública e de capacitar os profissionais para trabalhar com programas, a fim de efetivar o novo modelo assistencial e de reconhecer si tuações de vulnerabilidade social e em saúde.

Palavras-chave Gerenciamento, Saúde da família, Sistema municipal de saúde 
Introdução

Os serviços públicos de saúde estão, cada vez mais, sendo alvo de discussões no que diz respeito à qualidade do atendimento prestado, acesso e escuta qualificada, solução dos problemas identificados e encaminhamentos resolutivos. 0 processo de municipalização da saúde faz parte do movimento de reforma administrativa brasileira e devecontar com uma gestão capaz de atender uma perspectiva democrática, participativa, tecnicamente competente eeficiente.

0 conhecimento das tecnologias de gerenciamento em saúde para os municípios torna-se essencial, visto que, historicamente, a gerência era apenas executora das ações planejadas no âmbito federal, não acumulando experiências em planejar, desenvolver e avaliar políticas de saúde. 0 processo de descentralização do sistema único de saúde coloca a competência gerencial como um fator preocupante para a implementação de um sistema regionalizado, hierarquizado e participativo. Particularmente, a partir de agora, o Sistema Único de Saúde (SUS) tem no financiamento de recursos, na responsabilidade degestão eno pacto entregestores, seu ponto de partida para 0 atendimento das necessidades da população, nos vários níveis de complexidade'.

A atenção básica coordena os demais níveis do sistema de saúde, abordando problemas comuns da comunidade, priorizando os serviços de prevenção, promoção, cura, reabilitação visando à saúde e o bem-estar da população. Para atender a meta pactuada internacionalmente de saúde para todos no ano 2000, o Brasil implementou, em 1991, o Programa de Agentes Comunitários de Saúde (PACS), objetivando qualificar 0 acesso e a assistência. 0 amadurecimento da proposta implantada no país fez com que os técnicos apresentassem o Programa de Saúde da Família (PSF), em 1994, como uma estratégia de reorientação do modelo assistencial, em consonância com os princípios do SU S2. O PSF surge em substituição ao modelo hospitalocêntrico, centrado no indivíduo, no mecanicismo e no especialismo, passando a enfocar sua atenção no indivíduo na família e na comunidade, permitindo 0 aprimoramento e a consolidação do SUS e a reorientação da assistência ambulatorial e domiciliar. A família passa a ser o objeto principal de atenção, entendida a partir do ambienteno qual vive a população. 0 conceito de território é introduzido, demonstrando a sua importância, pois é nesse espaço que se constroem as relações intra e extra familiares e onde se desenvolve a luta pela melhoria da qualidade de vida ${ }^{3}$.
Para os secretários estaduais de saúde, a atenção primária "é um conjunto de intervenções no âmbito individual e coletivo, na busca de promoção, prevenção, diagnóstico, tratamento e reabilitação", tomando por base o contexto sociocultural do indivíduo eo sujeito em sua singularidade, complexidade e integralidade. Esta é desenvolvida por profissionais que desenvolvem práticas gerenciais e sanitárias, democráticas e em cooperação com populações de territórios delimitados ${ }^{4}$.

A reorientação das funções gerenciais pode ser vista como uma das estratégias para a consolidação dos princípios do SUS e transformação das práticas de saúde, criando condições para o direcionamento do processo de trabalho, para o desenvolvimento de serviços, aplicação de recursos necessários, melhoria nas relações interpessoais, resolutividade e satisfação dos usuários. A gerência possui um caráter articulador e integrativo, sendo a ação gerencial determinada e determinante no processo de organização de serviços de saúde eum instrumento para e efetivação das políticas. Podese dizer que a gerência não compreende uma ação simplesmenteracional ou técnica e, sim, apresenta dimensões científicas, técnicas eartísticas 5 .

A capacidade de gerenciar uma equipe de saúde e atender as perspectivas dos usuários requer um profissional equilibrado, que consiga superar as limitações que o serviço apresenta e que, além de prestar assistência baseada nos princípios do SUS, consiga lidar com o déficit de pessoal, de materiais, de recursos, bem como com a demanda cada vez maior de usuários. Além disso, o profissional atuante na gerência de serviços de saúde precisa ter competência para trabal har os relacionamentos interpessoais no interior das organizações, minimizando os conflitos existentes. Competência gerencial, determinação no alcance de metas e objetivos, personalidade e habilidade com pessoas são características determinantes para a resolutividade das ações, motivação da equipe esatisfação do usuário.

As competências gerenciais constituem um dos principais pilares de uma organização $0^{6-8}$. Pode-se definir competência como o "conjunto de características percebidas nas pessoas que envolvem conhecimentos, habilidades e atitudes que levam a um desempenho superior" 9 . Os componentes necessários às competências envolvem o conhecimento, 0 "saber" adquirido; as atitudes, que são ligadas à personalidade; e as habilidades, 0 "saber fazer", isto é, o saber fazer colocado em prática, portanto a competência de mobilizar recursos $s^{9.12}$.

Este estudo procura delimitar o papel dos gerentes da atenção básica e verificar as competências, atribuições e habilidades gerenciais necessá- 
rias, uma vez que possuem a função de coordenação do sistema municipal de saúde brasileiro e da porta de entrada deste sistema. Dentre os objetivos do estudo, encontram-se conhecer o perfil dos profissionais atuantes na gerência da atenção básica do município de Caxias do Sul (RS); verificar as competências, atribuições e habilidades gerenciais necessárias ao desempenho de suas funções, segundo a percepção destes; identificar as dificuldades e facilidades em relação ao desenvolvimento de suas atribuições; elevantar as dificuldades relativas à gestão de pessoas.

0 estudo justifica-se pelo interesse em conhecer as dificuldades enfrentadas pelos gerentes de unidades básicas de saúde e identificar as competências desenvolvidas pela gerência ${ }^{10,13,14}$, frente ao novo panorama das políticas públicas de saúde e da mudança do modelo assistencial, que colocam a gerência frente a responsabilidades e compromissos com a gestão das três esferas de governo.

\section{Métodos}

A pesquisa é um estudo de caso, realizada no município de Caxias do Sul, localizado na região da serra do Estado do Rio Grande do Sul, situado a 130 quilômetros da capital gaúcha. Segundo dados do IBGE (Instituto Brasileiro de Geografia e Estatística), o município conta com 404.187 habitantes. 0 público-alvo foi todos os gerentes das unidades básicas de saúde (UBS), totalizando 35 gerentes responsáveis por 39 UBS, sendo que alguns gerentes ficam responsáveis por duas UBS quando abrangem uma pequena área territorial. Há 26 equipes de Saúde da Família distribuídas nas 39 unidades básicas de saúde, respeitando 0 perfil epidemiológico e demográfico da população em regiões consideradas prioritárias para o desenvolvimento de ações em saúde.

0 instrumento de coleta utilizado foi um questionário semi-estruturado, aplicado às gerências das unidades básicas de saúde de Caxias do Sul no mês de novembro de 2006. A entrevista foi realizada para a aplicação do instrumento de coleta, sendo esta uma das técnicas mais utilizadas nos trabalhos de campo, em que o pesquisador faz perguntas abertas e fechadas ao entrevistado, dando a ele a possibilidade de expor o tema proposto ${ }^{15}$. Também foi utilizada uma escala de Likert, adaptada segundo a distribuição de Ávila ${ }^{16}$, composta por trinta variáveis agrupadas em três dimensões, a saber: habilidades, atribuições e competências desenvolvidas pelos gerentes de serviços de atenção básica. As respostas da escala de cinco pontos variaram entrenunca; quasenunca; indeciso; quase sempre, sempre e sem resposta. A escala de Likert consiste em vários enunciados que expressam um ponto de vista sobre determinado tópico. É solicitado aos entrevistados que indiquem em que grau concordam ou discordam com a opinião expressa pelo enunciado ${ }^{17}$.

Quanto ao tratamento dos dados, foi utilizada a análise descritiva para os dados qualitativos. Utilizou-se a análise de conteúdo, sendo entendida como "um conjunto de técnicas de análise das comunicações" ${ }^{18}$. A análise de conteúdo trabalha com a categorização que emerge da fala dos sujeitos. A categorização tem como objetivo fornecer uma representação simplificada dos dados brutos ${ }^{18}$. A análise foi dividida em categorias iniciais, representada pelas falas dos sujeitos da pesquisa; intermediárias, dividindo as categorias iniciais em três blocos conforme os objetivos da pesquisa; efinais, retornando ao todo por meio de uma síntese das descrições, significando, portanto, produto da análisequalitativa.

Para os dados quantitativos, foi utilizado 0 programa SPSS 10.0 for Windows; foi realizada a análise univariada para os dados demográficos e para as variáveis contidas na escala de Likert. Foi solicitada a autorização ao ComitêdeÉtica em Pesquisa da Secretaria M unicipal de Saúde de Caxias do Sul e elaborado um termo de consentimento livreeesclarecido que foi oferecido aos participantes da pesquisa, conforme a as diretrizes enormas regulamentadoras de pesquisa envolvendo seres humanos especificadas na Resolução 196/9619.

\section{Resultados}

Foram entrevistadas 29 gerentes das unidades básicas de saúde. As perdas somaram 17,1\% e foram ocasionadas pelo fato de alguns gerentes estarem de férias ou não terem comparecido no dia da realização das entrevistas. Todos entrevistados são do sexo feminino, com idade média de 44 anos. Q uanto à experiência em saúde pública, 13,8\% atuam em saúde pública há menos de cinco anos, $51,7 \%$, de seis a dez anose $31 \%$, um tempo superior a onze anos. A maioria destas, ou seja, $89,7 \%$, estão no cargo de gerência há menos de dois anos e 6,9\%, a um tempo superior a seis anos.

Quanto à escolaridade, verificou-se que todas as gerentes possuem ensino superior completo e $62,1 \%$ possuem pós-graduação. As áreas de pósgraduação incluem saúde do trabalhador $(27,8 \%)$, enfermagem obstétrica $(22,2 \%)$, terapia intensiva (11,1\%), saúde pública (11,1\%), saúde da família 
$(5,6 \%)$, sanitarista $(5,6 \%)$, acupuntura $(5,6 \%)$ e nefrologia (5,6\%).

Quanto às ações desenvolvidas pelas gerências, $100 \%$ delas realizam sempre ou quase sempre as ações referentes às habilidades gerenciais, que abrangem a comunicação, a organização de tarefas, o planejamento de ações ea negociação. Q uanto à tomada de decisão para a solução de problemas, $6,9 \%$ permaneceram indecisas e $93,1 \%$ referiram não ter dificuldades quanto a esta questão. A utilização de tecnologias leves (acolhimento, vínculo, resolutividade) eduras (utilização de tecnologiase entendimento geral dos equipamentos) que fazem parte das habilidades gerenciais apresentaram poucas diferenças, embora consistentes, visto que $96 \%$ das gerentes utilizam as tecnologias leves nos seus processos de trabalho e $72,4 \%$ das gerentes fazem uso das tecnologias duras, sendo que $27,6 \%$ não utilizam equipamentos em geral, incluindo o uso de computadores (Tabela 1).

Quanto às atribuições dos profissionais que atuam na atenção básica, verificou-se que $86,2 \%$ referem ter autonomia para a realização de ações nas suas unidades de saúde. Para o desenvolvimento de atividades preventivas, grupos de convivência, auxílio à criança vítima de maus tratos, $86,3 \%$ referiram que sempre ou quase sempre mantêm articulação com organizações governamentais e $75,8 \%$ referiram que mantêm articulação com organizações não governamentais para o desenvolvimento de grupos de convivência, arteterapia, doações e atendimento das necessidades da comunidade. Quanto à real ização de análise das condições de saúde, problemas enecessidades da população com base no sistema de informação e por meio de dados epidemiológicos, 6,9\% dos gerentes não responderam, 6,9\% permaneceram indecisos, 10,3\% responderam que nunca ou quase nunca e $75,9 \%$ responderam que sempre ou quase sempre realizam esta análise (Tabela 2).

Quanto à programação e controle das ações de vigilância epidemiológica, 82,7\% das gerentes responderam que desenvolvem ações de vigilância epidemiológica sempre ou quase sempre. Em relação à vigilância sanitária, 31\% responderam que nunca ou quase nunca e $10,3 \%$ permaneceram indecisos. A grande parte das gerentes $(93,1 \%)$ desenvolvem ações programáticas dirigidas à saúde da criança, adolescente, mulher, idoso, entre outras. A programação econtrole deações no atendimento à demanda espontânea, através do acolhimento, humanização na porta de entrada e sala de espera é realizada sempre ou quase sempre por $89,7 \%$ das gerentes. 0 gerenciamento de materiais, insumos e medicamentos são realizados por 79,3\% das gerentes sempre ou quase sempre (Tabela 2).

Em relação às competências desenvolvidas pela gerência, verificou-se quea liderança é desenvolvida sempre ou quase sempre por $89,6 \%$ das gerentes. Já o gerenciamento de conflitos, o trabalho em equipe, a aceitação das diferenças étnicas, sociais e educacionais, a resiliência, o preenchimento dos relatórios do Sistema de Informação de Atenção Básica (SIAB) e do Programa de Saúde da Família, a alocação de materiais e de recursos humanos são desenvolvidos por $93,1 \%$ das gerentes. 0 julgamento do conjunto de procedimentos, ferramentas e equipamentos, incluindo computadores e seus programas necessários para o desenvolvimento do processo de trabalho, são realizados sempre ou quase sempre por $65,6 \%$ dos gerentes. Já a compreensão dos procedimentos adequados para estabelecer e operar máquinas, incluindo computadores, é realizada sempre ou quase sempre por $58,6 \%$ da gerência (Tabela 3 ).

Tabela 1. Distribuiç̧ão das variáveis relativas às habilidades apresentadas pelas gerentes de Unidades Básicas de Saúde. Caxias do Sul, 2006.

\begin{tabular}{|c|c|c|c|c|c|c|}
\hline Habilidades & $\begin{array}{c}\text { nunca } \\
(\%)\end{array}$ & $\begin{array}{c}\text { quase } \\
\text { nunca (\%) }\end{array}$ & $\begin{array}{c}\text { indeciso } \\
(\%)\end{array}$ & $\begin{array}{c}\text { quase } \\
\text { sempre (\%) }\end{array}$ & $\begin{array}{c}\text { sempre } \\
(\%)\end{array}$ & $\begin{array}{c}\text { sem resposta } \\
(\%)\end{array}$ \\
\hline Comunicação & - & - & - & 79,3 & 20,7 & - \\
\hline Organização & - & - & - & 58,6 & 41,4 & - \\
\hline Planejamento & - & - & 10,3 & 58,6 & 31,0 & - \\
\hline Tomada de decisão para solução de problemas & - & - & 6,9 & 65,5 & 27,6 & - \\
\hline Utilização de tecnologias leves & - & 3,4 & - & 37,9 & 58,6 & - \\
\hline U tilização de tecnologias duras & 3,4 & 13,8 & 6,9 & 51,7 & 20,7 & 3,4 \\
\hline N egociação & - & - & 6,9 & 48,3 & 44,8 & - \\
\hline
\end{tabular}

Fonte: Pesquisa, novembro de 2006. 
Tabela 2. Distribuição das variáveis relativas às atribuições apresentadas pelas gerentes de Unidades Básicas de Saúde. Caxias do Sul, 2006.

\begin{tabular}{lcccccc}
\hline \multicolumn{1}{c}{ Atribuições } & $\begin{array}{c}\text { nunca } \\
(\%)\end{array}$ & $\begin{array}{c}\text { quase } \\
\text { nunca (\%) }\end{array}$ & $\begin{array}{c}\text { indeciso } \\
(\%)\end{array}$ & $\begin{array}{c}\text { quase } \\
\text { sempre (\%) }\end{array}$ & $\begin{array}{c}\text { sempre } \\
(\%)\end{array}$ & $\begin{array}{c}\text { sem resposta } \\
(\%)\end{array}$ \\
\hline Autonomia & - & 10,3 & - & 58,6 & 27,6 & 3,4 \\
$\begin{array}{l}\text { Articulação com organizações } \\
\text { governamentais }\end{array}$ & - & 10,3 & - & 44,8 & 41,4 & 3,4 \\
$\begin{array}{l}\text { Articulação com organizações não } \\
\text { governamentais }\end{array}$ & 6,9 & 13,8 & 3,4 & 51,7 & 24,1 & - \\
$\begin{array}{l}\text { Análise das condições de saúde, } \\
\text { problemas e necessidades }\end{array}$ & 3,4 & 6,9 & 6,9 & 58,6 & 17,2 & 6,9 \\
$\begin{array}{l}\text { Programação e controle: das ações } \\
\text { de vigilância epidemiológica }\end{array}$ & - & 6,9 & 6,9 & 51,7 & 31,0 & 3,4 \\
$\begin{array}{l}\text { Programação e controle das ações } \\
\text { de vigilância sanitária }\end{array}$ & 3,4 & 27,6 & 10,3 & 34,5 & 20,7 & 3,4 \\
$\begin{array}{l}\text { Programação e controle de ações } \\
\text { programáticas: dirigidas à saúde da criança, }\end{array}$ & - & - & 6,9 & 55,2 & 37,9 & - \\
$\begin{array}{l}\text { adolescente, mulher, idoso, etc. } \\
\begin{array}{l}\text { Programação e controle da execução de ações } \\
\text { no atendimento à demanda espontânea }\end{array}\end{array}$ & - & 6,9 & - & 41,4 & 48,3 & 3,4 \\
$\begin{array}{l}\text { Gerenciamento de materiais, insumos } \\
\text { e medicamentos }\end{array}$ & - & 3,4 & 3,4 & 13,8 & 65,5 & 13,8 \\
\hline
\end{tabular}

Fonte: Pesquisa, novembro de 2006.

Tabela 3. Distribuição das variáveis relativas às competências apresentadas pelas gerentes de Unidades Básicas de Saúde. Caxias do Sul, 2006.

\begin{tabular}{|c|c|c|c|c|c|c|}
\hline Competências & nunca & & indeciso & quase & sempre & em resposta \\
\hline Liderança & - & - & 3,4 & 44,8 & 44,8 & 6,9 \\
\hline Gerencia conflitos & - & - & & 44,8 & 48,3 & 6,9 \\
\hline Participa de trabalho em equipe & - & - & 3,4 & 34,5 & 58,6 & 3,4 \\
\hline Aceita diferenças & - & 3,4 & 3,4 & 27,6 & 65,5 & - \\
\hline Demonstra resiliência & - & 3,4 & 3,4 & 65,5 & 27,6 & - \\
\hline Acomoda mudanças & - & - & 3,4 & 55,2 & 41,4 & - \\
\hline M otivação & - & - & - & 34,5 & 62,1 & 3,4 \\
\hline Preenchimento dos relatórios do SIAB e PSF & 3,4 & 3,4 & - & 17,2 & 75,9 & \\
\hline Alocação de materiais & - & 3,4 & - & 31,0 & 62,1 & 3,4 \\
\hline Alocação de recursos humanos & - & 3,4 & 3,4 & 58,6 & 34,5 & - \\
\hline Monitora e corrige desempenho & 3,4 & 3,4 & 6,9 & 31,0 & 51,7 & 3,4 \\
\hline $\begin{array}{l}\text { Julga qual o conjunto de procedimentos, } \\
\text { ferramentas e equipamentos necessários, } \\
\text { incluindo computadores e seus programas }\end{array}$ & - & 13,8 & 10,3 & 27,6 & 37,9 & 10,3 \\
\hline $\begin{array}{l}\text { Compreende a intenção geral e os } \\
\text { procedimentos adequados para estabelecer e } \\
\text { operar máquinas, incluindo computadores }\end{array}$ & - & 10,3 & 20,7 & 20,7 & 37,9 & 10,3 \\
\hline $\begin{array}{l}\text { Previne, identifica e soluciona problemas em } \\
\text { máquinas e computadores }\end{array}$ & 10,3 & 6,9 & 17,2 & 31,0 & 34,5 & - \\
\hline
\end{tabular}

Fonte: Pesquisa, novembro de2006. 
Foram realizadas três perguntas abertas para as gerentes, nas quais sequestionou 0 entendimento sobre o conceito de gerência, os meios facilitadores edificultadores para a realização de suas atribuições e as dificuldades em relação à gestão de pessoas. Quanto ao conceito de gerência, foram destacadas as descrições abaixo:

Gerência éa coordenação das atividades dos diversos profissionais, para que harmonizados entre si, resultem em qualidade dos serviços prestados, bem como a articulação dos serviços com a instância administrativa. É coordenar uma equipe e estar aberto a mudanças, saber ouvir, reconhecer e estar presente no dia a dia da UBS. Ser comprensivo eresolutivo. Respeitar as normas da instituição, acreditar nestas normas para que as pessoas que trabalhem conosco possam também seguir as regras. (Entrevistas no 1 e 9)

Gerenciar pessoas para a coordenação das atividades desenvolvidas é diferente de gerenciar com pessoas, ou seja, no primeiro caso as pessoas são o objeto da gerência, são guiadas e controladas pela gerência para o alcance dos objetivos propostos; já no segundo, as pessoas são o sujeito ativo da gerência responsáveis pela direção e controle dos objetivos individuais e organizacionais ${ }^{20}$. Gerenciar é pensar, ouvir, fazer acontecer e obter resultados que, após serem definidos, analisados e avaliados, devem ser alcançados através das pessoas envolvidas, em constante interação. Então, podese dizer que a gestão deve ser compreendida como técnica, sendo esta relacionada ao domínio de técnicas administrativas, permitindo a compreensão, o manejo e a solução de problemas; e criativa, esta relacionada a situações que requerem a interação humana e conferem a dimensão do intuitivo, do emocional e do espontâneo ${ }^{21}$.

As pessoas são administradas por gerentes com base em diretrizes e práticas emanadas pelo órgão competente. 0 gerente é o responsável pelo desenho do trabalho a ser realizado, pela escolha epreparo da equipe, assim como liderá-la, motivá-la, avaliá-la e recompensá-la adequadamente para, então, poder gerenciá-la e dela obter eficiência no desenvolvimento de suas ações e efetividade nos resultados. Para o autor Lazzarotto, "lidar com pessoas é uma tarefa altamente complexa. E, sobretudo, gratificante para quem souber fazêlo deforma a enaltecer o trabal ho e dignificar o ser humano"22.

Outros dois gerentes consideram a gerência um cargo que exige a capacidade detrabalhar com conflitos e consideram a gerência como um equilíbrio na relação entre a comunidade e o gestor. Segue a descrição: Gerência é coordenar um serviço, uma área de abrangência, lidar com conflitos, procurar soluções, inserir o serviç̧o dentro da comunidade, ser o elo com o órgão gestor, procurando trabalhar bem dentro da sua realidade, estimulando a equipea dar o melhor de si. (Entrevista $\mathrm{n}$ - 10)

As funções de gerência e de gestão se confundem no que diz respeito às suas funções. A gerência é tida como a administração de uma unidade ou órgão de saúde, representando as necessidades e os interesses da comunidade. Ela indica as atividades que precisarão ser desenvolvidas com o propósi to de assegurar a condução, a programação, 0 controle e a avaliação das ações em saúde com re sultados positivos e satisfação das necessidades da população. Já o gestor é o indivíduo que ocupa uma posição estratégica no sistema de decisões e responde pela formulação e implementação das políticas de saúde a nível local, exercendo as funções de coordenação, articulação, negociação, planejamento, acompanhamento, controle, avaliação e autonomia ${ }^{23-25}$.

Pode-se perceber que o papel da gerência não é apenas descrever dados, servir deelo entreo gestor e a comunidade local e coordenar uma equipe. É preciso realizar a análise das informações, relacionar fatores que precisam ser trabalhados com a população e trabalhar em conjunto com os interesses da comunidade, na busca de soluções para os problemas identificados, em consonância com os interesses do gestor, por meio de negociações e discussão de prioridades, além de possuir habilidades para liderar pessoas e motivar a equipe a fim de alcançar as metas propostas.

Quanto aos meios facilitadores para a realização de suas atribuições, foi ressaltada a presença de uma equipe coesa; a elaboração dos planos locais de saúde e de atividades programadas com antecedência; 0 apoio dos núcleos que ajudam a esclarecer e dão suporte em várias decisões; as capacitações realizadas; a autonomia nas atividades internas da UBS; a população da UBS; o perfil do profissional; o conhecimento da função, dos fluxos e da legislação; a presença de profissionais como assistente social e psicóloga; e estar presente na unidade diariamente. Seguem algumas descrições: 0 que facilita é uma equipe coesa e integrada. A equipe que é muito boa e unida, a população da UBS e o meu perfil. 0 apoio conseguido com a comunidade local, a realização dos planos locais, atividades programadas com antecedência. (Entrevistas 느 4, 6 e 12)

Em relação aos meios dificultadores, 0 excesso de burocracia, a pequena área física, o gerenciamento de recursos humanos, a sobrecarga de atividades assistenciais e de coordenação e a falta de rede informatizada nas unidades apareceram com mais frequência. As decisões centralizadas; a polí- 
tica partidária; a mudança de governo; a demora das respostas pela Secretaria M unicipal deSaúde; e não ter formação específica em gerenciamento também foram citadas. Segue a manifestação de três gerentes em relação à sobrecarga de atividades burocráticas: [...] o que dificulta é a sobrecarga de atividades assistenciais e de coordenação. [...] não temos computador, tudo é manual, não tem funcionário para burocracia, tudo é realizado pela equipe de enfermagem, não temos nem telefonista. [...] falta de estrutura física e recursos humanos. (Entrevista $\mathrm{n}-4,7$ e26)

Q uanto às dificuldades em relação à gestão de pessoas foram citados os recursos humanos insuficientes com número de usuários superior à capacidade da equipe, acarretando sobrecarga de atividades; pouco compromisso de al guns; pessoas que não aceitam mudanças; a visão diferente de muitos profissionais, que acabam priorizando os interesses individuais aos coletivos; e a dificuldade em conseguir contentar a todos, salientado nas descrições a seguir: [...] pessoas com opinião divergente ou que não querem somar com a equipe. [...] temos dificuldade quanto à área física, número reduzido de profissionais para atender as necessidades da comunidade. [...] recursoshumanos insuficientes esem perfil para a função e dificuldades para a troca. [...] trabalhadores pouco comprometidos, profissionais sem formação para trabalhar no PSF, trabalhadores com dificuldade em respeitar hierarquia. [...] dificuldade em aderir a mudanças por muitos profissionais. (Entrevista no 4, 7, 8, 13 e 14)

O utras dificuldades em relação à gestão de pessoas encontradas foram a ausência de medidas de punição no serviço público; as relação entremembros da equipe; recursos humanos sem perfil esem formação para trabalhar no PSF; pouco tempo disponível para diálogo entre os funcionários; ausência de um programa de avaliação permanente dos funcionários e um plano de carreira, cargos e salários; resistência usando a estabilidade em favor próprio; dificuldades para transferir o servidor ou conseguir substituição; pessoas que não aceitam as limitações dos membros da equipe; e pessoas desmotivadas. N ota-se a descrição de uma gerente: [...] cada ser humano tem uma maneira de ser própria, e coordenar um grande número de pessoas diferentes não é fácil. Requer paciência, habilidade, controle emocional emuita perseverança. (Entrevista $\mathrm{n}-12$ )

A síntese dos dados apresentados acima foi organizada em categorias iniciais, intermediárias e finais. A categorização representa o produto do tratamento dos dados qualitativos que emergiram das falas dos entrevistados. Objetivando apresentar didaticamente a construção das mesmas, foi construído o Quadro 1.

\section{Discussão}

Pode-se perceber que a maioria das gerentes entrevistadas possui um tempo de experiência de 6 a 10 anos em saúde pública, porém estão no cargo de gerência a menos de 2 anos. A maioria possui pósgraduação, no entanto, somente $11,1 \%$ possuem pós-graduação em saúde pública e 5,6\% em saúde da família. Além disso, al gumas descreveram como dificuldadepara a realização de suas atribuições não ter formação específica em gerenciamento. Percebe-se que, apesar da experiência em saúde pública, há a necessidade de formação específica para a área de saúde coletiva, direcionado para o novo modelo de atenção básica e de gerenciamento de recursos, sejam eles, humanos, materiais ou financeiros.

Por outro lado, todas as gerentes são dotadas de habilidades gerenciais, que abrangem a comunicação, a organização de tarefas, o planejamento de ações e a negociação. Pode-se entender por comunicação a troca de informações, fatos, idéias e significados e pode ser utilizado para informar, coordenar e motivar as pessoas, sendo esta, uma das competências gerenciais menos compreendidas e mais importantes, pois saber como equando compartilhar informações requer a compreensão das pessoas e situações ${ }^{26}$.

A comunicação interpessoal einterprofissional é um fenômeno fundamental no processo de trabalho, sendo que o modo como uma idéia é transferida interfere no comportamento do mesmo, pois ao desqualificar as informaç̧ões, o processo deconstrução desujeitosfica comprometido, constituindo pessoas sujeitadas ao trabalho e não sujeitos de ação. $N$ ão énecessário somente organizar o serviço para obter eficácia e eficiência nas ações desenvolvidas, mas construir sujeitos sociais de práticas singulares ${ }^{27}$. $\mathrm{N}$ ão basta apenas trabalhar com interdisciplinaridade, é necessário trocas intersubjetivas e comunicação interprofissional ${ }^{28}$.

0 planejamento das ações é realizado por todas as gerentes entrevistadas, porém a análise das condições de saúde, problemas e necessidades da população com base no sistema de informação e por meio de dados epidemiológicos, é realizado sempre ou quase sempre, por $75,9 \%$ das gerentes, visto que para concretizar um bom planejamento é fundamental realizar um diagnóstico da comunidade, com base nos problemas levantados. 
Quadro 1. Categorias de análise construídas a partir da percepção dos entrevistados.

\begin{tabular}{|c|c|c|}
\hline Categorias iniciais & $\begin{array}{c}\text { Categorias } \\
\text { intermediárias }\end{array}$ & Categorias finais \\
\hline $\begin{array}{l}\text { Equipe coesa } \\
\text {. Elaboração dos planos locais de saúde } \\
\text {. Apoividades dos núcleos que ajudam a esclarecer e dão } \\
\text { suporte em várias decisões } \\
\text {. Capacitações realizadas } \\
\text { - Autonomia nas atividades internas da UBS } \\
\text {. População da UBS } \\
\text { - Perfil do profissional } \\
\text {. Conhecimento da função, dos fluxos e da } \\
\text { legislação } \\
\text { e Presença de profissionais como assistente social } \\
\text { e psicólogo } \\
\text {. Estar presente na unidade diariamente }\end{array}$ & $\begin{array}{l}\text { M eios facilitadores para a } \\
\text { realização das atribuições }\end{array}$ & $\begin{array}{l}\text { Equipe coesa, } \\
\text { planejamento e } \\
\text { autonomia nas } \\
\text { atividades da UBS }\end{array}$ \\
\hline $\begin{array}{l}\text { Excesso de burocracia } \\
\text {. Área física pequena } \\
\text {. Gerenciamento de recursos humanos } \\
\text {. Sobrecarga de atividades assistenciais e de } \\
\text { coordenação } \\
\text {. Falta de rede informatizada nas unidades } \\
\text {. Decisões centralizadas } \\
\text {. Política partidária } \\
\text { - Mudança de governo } \\
\text {. Demora das respostas pela Secretaria M unicipal } \\
\text { de Saúde } \\
\text {. Não ter formação específica em gerenciamento }\end{array}$ & $\begin{array}{l}\text { M eios dificultadores } \\
\text { para a realização } \\
\text { das atribuições }\end{array}$ & $\begin{array}{l}\text { A estrutura como } \\
\text { condicionante } \\
\text { para a realização } \\
\text { das atribuições } \\
\text { dos gerentes }\end{array}$ \\
\hline $\begin{array}{l}\text { Recursos humanos insuficientes } \\
\text {. Número de usuários superior à capacidade da } \\
\text { equipe. Sobrecarga de atividades } \\
\text {. Pouco compromisso de al guns } \\
\text {. Pessoas que não aceitam mudanças } \\
\text {. Profissionais com diferentes visões que acabam } \\
\text { priorizando os interesses individuais aos coletivos } \\
\text {. Dificuldade em conseguir contentar a todos } \\
\text {. Ausência de medidas de punição no serviço } \\
\text { público } \\
\text {. Relações interpessoais } \\
\text {. Recursos humanos sem perfil e sem formação } \\
\text { para trabalhar no PSF } \\
\text {. Pouco tempo disponível para diálogo entre os } \\
\text { funcionários } \\
\text {. Ausência de um programa de avaliação } \\
\text { permanente dos funcionários e um plano de } \\
\text { carreira, cargos e salários } \\
\text {. Resistência usando a estabilidade em favor } \\
\text { próprio } \\
\text {. Dificuldades para transferir o servidor ou } \\
\text { conseguir substituição } \\
\text {. Pessoas que não aceitam as limitações dos } \\
\text { membros da equipe } \\
\text {. Pessoas desmotivadas }\end{array}$ & $\begin{array}{l}\text { Dificuldades em } \\
\text { relação à gestão de } \\
\text { pessoas }\end{array}$ & $\begin{array}{l}\text { Falta de } \\
\text { comprometimento } \\
\text { e motivação dos } \\
\text { trabalhadores }\end{array}$ \\
\hline
\end{tabular}

Fonte: Pesquisa, N ov 2006. 
As tecnologias leves são utilizadas por $96,5 \%$ das gerências, sendo estas, imprescindíveis no processo de trabalho entre os profissionais e destes com os usuários. Astecnologias leves se referem ao compromisso com a vida, expressa em atos assistenciais do trabal ho vivo em saúde, como a relação de acolhimento, a criação do vínculo, a resolutividade e a criação de maiores graus de autonomia29. A produção de tecnologias leves são importantes ferramentas de gerenciamento utilizadas rumo à qualidade da assistência prestada. Seu uso contempla um objeto queexigeuma capacidadediferenciada no olhar a fim de que se possa perceber a pluralidade que desafiam os sujeitos à criatividade, à escuta e à flexibilidade ${ }^{29,30}$. Já as tecnologias duras perfazem um uso de $72,4 \%$ pelas gerentes, devido indisponibilidadedeequipamentostecnológicos em geral nas unidades, principalmentecomputadores. M uitas delas ressaltam que a rede não é informatizada e não há computadores nas unidades básicas de saúde.

A falta de uma rede informatizada éum grande problema na atenção básica, impossibilitando que os profissionais atuantes nas comunidades locais lancem os dados dos relatórios preenchidos no SI AB e analisem as condições de saúde da população de interesse, com base em dados estatísticos e epidemiológicos. Além disso, nega aos profissionais a prática de trabalhar com programas informatizados, visto que muitos possuem dificuldade em trabalhar com computadores.

Alguns fatores responsáveis pela subnotificação de informações no SIAB são a pouca importância dada pelos gestores sobre a capacidade potencial eatual do SI AB, capacitação insuficientedas equipes para operar e utilizar as informações produzidas e falhas no processo de coleta, na periodicidade eno fluxo de dados. Acredita-se queos profissionais desconhecem a real importância da utilização da informação como instrumento de negociação e transformação fundamental para o trabaIho na atenção básica ${ }^{31}$.

Alguns gerentes referem ter autonomia para a realização de suas atribuições nas atividades internas e rotinei ras da UBS, mas quanto à decisão de outras ações, é necessária a avaliação do gestor municipal de saúde. Existem governos locais responsáveis e comprometidos com a eficiência da gestão e 0 atendimento dos cidadãos por motivos programáticos ou pela qualidade moral de seus governantes, porém sabe-se que este exemplo não é visto sempre na prática. A autonomia da gestão local cria oportunidades para que os gestores locais implementem decisões de acordo com suas próprias preferências que, muitas vezes, não são necessariamente condizentes com os interesses da populaçãa ${ }^{32}$.

Por outro lado, outros gerentes salientam que existem atividades que já vêm programadas e a UBS realiza conformeorientação dada. Porém, vale questionar se os profissionais atuantes na gerência possuem conhecimento de suas verdadeiras atribuições, não ultrapassando aquilo que é de sua competência. Com o avançar dos anos, as formas verticalizadas de gestão e de gerência vão sendo substituídas por relações horizontais, culminando com a diminuição das funções de chefia e a introdução de sistemas mais participativos e abertos de decisão, levando a uma participação do trabalhador nos interesses do serviço ${ }^{21}$.

0 gerenciamento de materiais, insumos e medicamentos, são realizados, sempre ou quase sempre, por $79,3 \%$ das gerentes. A administração de recursos materiais tem sido motivo de preocupação no setor público, devido à restrição de orçamentos, ocasionando um maior controle do consumo e dos custos. Assim, é necessário o aprimoramento dos sistemas de gerenciamento desses re cursos materiais para garantir uma assistência contínua de qualidade e menor custo ${ }^{33}$.

Em relação às competências, observou-se que a liderança, o gerenciamento de conflitos, o trabaIho em equipe, a resiliência e a alocação de materiais e de recursos humanos, são desenvolvidos pela maioria das gerentes.

A liderança é considerada um processo de influência interpessoal eocorre dentro deum contexto, pois não depende somente das características individuais do gerente, mas da situação em que se encontra. 0 processo decomunicação éo meio pelo qual o líder é capaz de influenciar pessoas, visando à consecução de um ou de diversos objetivos específicos ${ }^{34}$. Já a resiliência está relacionada à noção de sucesso e de adaptação às normas sociais. Segundo Yunes, resiliência é um fenômeno que procura explicar os processos de superação de adversidades. Para Flach, resiliência éo termo aplicado ao indivíduo que tem habilidade para reconhecer a dor, entender seu sentido etolerá-la atéresolver os problemas e conflitos de forma construtiva ${ }^{35}$.

Os conflitos entre indivíduos podem ter consequências positivas ou negativas. Eles podem ser explorados a partir da compreensão de como eles surgem e evoluem. Os conflitos podem surgir por variados motivos, mas frequentemente, desenvolvem-se em consequência de diferenças individuais, como valores, atitudes, crenças, necessidades ou percepções, além de mal-entendidos e falhas na comunicação. A construção de uma equipe deve compreender como aproveitar as experiências, ca- 
pacidades e compromissos de cada componente para atingir as metas coletivas. 0 trabal ho em equipe é justificado por aproveitar os conhecimentos, competências e habilidades trazidos por cada pessoa ao local de trabalho ${ }^{27}$.

Para o trabalho em equipe ocorrer sistematicamente, é preciso trabalhar nos processos de criação, armazenamento, partilha e distribuição de conhecimento, a partir do desenvolvimento do capital humano, estrutural e relacional. Desenvolver o capital humano não significa obter somente um acréscimo na formação, mas desenvolver as competências individuais, por meio da mudança de atitude das pessoas, orientadas não apenas para o cumprimento deobjetivos previamentenegociados, mas igualmente com uma crescente autonomia e liberdade de ação, condições indispensáveis para o desenvolvimento de atos criativos. 0 de senvolvendo do capital estrutural pressupõea concepção de estruturas que estimulem a aprendizagem interna ao nível de todos os trabal hadores da atenção básica e o desenvolvimento do capital re lacional implica desenvolver permutas deinformação e conhecimento com o exterior ${ }^{36}$.

A motivação nos locais de trabalho é influenciada por fontes extrínsecas, que dizem respeito às forças externas à pessoa, e intrínsecas, que se refe rem às forças geradas pela própria pessoa. Desse modo, pode-se perceber que o indivíduo é motivado por uma série de necessidades. Os fatores que mais contribuem para a motivação no trabalho são oportunidades (educação, programas e oportunidades de treinamento), segurança no emprego, orgulho pelo trabalho, abertura/equidade (os mais al tos líderes são acessíveis para todos os funcionários), camaradagem eremuneração ou benefícios ${ }^{26}$.

As competências essenciais presentes nas organizações são aquelas difíceis de serem imitadas e são favorecidas pelas habilidades pessoais e interpessoais manifestadas pelo gerente. Estas incluem trabalho em equipe, habilidade para informar, pensamento sistêmico, habilidade para trabalhar com informações e tecnologia, criatividade na solução de problemas, habilidades de comunicação, autoconfiança e auto-estima. As atitudes permitem fazer uso do conhecimento, em busca da inovação e da aprendizagem permanentes, integrando aspec- tos técnicos, sociais e atitudes relacionadas ao trabalho desenvolvido. A formação de uma atitude é "resultado de crenças, reflexos condicionados, fixações, julgamentos, ester eótipos, experiências, exposições a comunicações persuasivas, trocas de informações e experiências com outros indivíduos"22.

Em suma, pode-se dizer que as maiores dificuldades encontradas pelas gerentes na realização de suas atribuições se relacionaram à estrutura, como 0 excesso de burocracia, à sobrecarga de atividades e à área física pequena, que, de alguma forma, dificulta o processo de trabalho da equipe, causando estresse e conflitos, tanto entre colegas, quanto destes com a comunidade. Muitas gerentes possuem dificuldade em trabalhar com tecnologias duras, como computadorese, consequentemente, manipular e analisar dados, a fim de trabalhar com dados em saúde. A falta de acesso a um sistema informatizado e não saber trabalhar com dados epidemiológicos gerauma deficiência nos processos de trabalho, prejudicando a nova lógica do modelo de atenção básica e o trabalho da equipe.

Em relação à gestão de pessoas, as categorias finais foram formadas por recursos humanos insuficientes que, na maioria das vezes, causam sobrecarga de atividades e estresse entre membros da equipe, bem como descontentamento e desmotivação, gerando desequilíbrio das relações de trabalho e formação de interesses próprios. Assim, a gerência de serviços precisa ter competência e habilidade para trabalhar as deficiências nos processos de trabal ho e exigir do sistema municipal, condições de trabalho satisfatórias, procurando motivar os profissionais atuantes nas unidades locais desaúde, a fim de prestar um atendimento qualificado e resolutivo.

Finalizando, pode-se dizer que os resultados foram os esperados, contando que os problemas com maior relevância se relacionaram à gestão de pessoas e às dificuldades em manipular e trabaIhar com equipamentos, mais precisamente computadores. Nota-se que há grande necessidade de informatizar a rede pública e capacitar os profissionais para trabal har com programas e dados epidemiológicos, a fim de efetivar o novo modelo de atenção básica e de reconhecer situações de vulne rabilidade social e em saúde. 


\section{Colaboradores}

LCL Fernandes elaborou a maior parte do estudo, incluindo a introdução, o referencial teórico, os métodos, os resultados e a discussão. RZ M achado orientou o estudo, colaborando em todas as etapas. GO Anschau realizou as entrevistas e colaborou na elaboração do referencial teórico.

\section{Referências}

1. Fraccolli LA, Ermel RC. Processo de trabalho de gerência: uma revisão da literatura. Escola Enfermagem USP 2003; 37(2):89-96.

2. Rosa WAG, Labate RC. Programa de Saúde da Família: a construção de um novo modelo de assistência. Rev Latino-am enfermagem 2005; 13(6):1027-1034.

3. Brasil. M inistério da Saúde. Saúde da Família: uma estratégia para a reorientação do modelo assistencial. Brasília: Ministério da Saúde; 1997.

4. Brasil. Conselho Nacional de Secretários de Saúde. Atenção Primária - Seminário do Conass para a construção de consensos/Conselho $\mathrm{N}$ acional de Secretários de Saúde. Brasília: CONASS; 2004.

5. Melo M LC, Nascimento MAA. Treinamento Introdutório para Enfermeiras Dirigentes: possibilidades para gestão do SUS. Revista Bras Enferm 2003: 56(6):674-677.

6. Thompson Jr, Arthur A, Strickland III AJ. Strategic $M$ anagement. $4^{\text {th }}$ ed. Homewood, IL: BPI/Irwin; 1987.

7. $\mathrm{M}$ intzberg $\mathrm{H}$. The $\mathrm{N}$ ature of $\mathrm{M}$ anagerial Work. $\mathrm{New}$ York: Harper \& Row; 1973.

8. Kotter J. "What leaders really do". Harvard Business Review 1990:103-111.

9. Boog GG, Boog M. M anual de gestão de pessoas e equipes: estratégias e tendências. Vol. 1. São Paulo: Gente; 2002.

10. Hofrichter, DA, Spencer JR, Lyle M. Competencies: the right foundation for effective human resource management. Compensation \& Benefits Review 1996; 28(6):21-23.

11. Le Boterf G. De la Compétence. Paris: Les Edition d'Organization; 1994.

12. Perrenoud PH. L'obligation de competences: une évaIuation en quête d'acteurs. Éducateur 1996; 11:23-29.

13. Gramigna M R. M odelo de competências e gestão dos talentos. São Paulo: Pearson Education; 2002.

14. Krogh G, Roos J. A perspective on knowledge, competence and strategy. Personal Review 1995; 24(3):56-76.

15. M inayo MCS. 0 desafio do conhecimento: pesquisa qualitativa em saúde. 6a ed. São Paulo: Hucitec; Rio de Janeiro: Abrasco; 1999.

16. Ávila DVB. 0 perfil do gestor de unidade básica de saúde: verificando competências e habilidades [monografia]. Porto Alegre (RS): Universidade Estadual do Rio Grande do Sul; 2005.

17. Polit $D$, Hungler $B$. Fundamentos de pesquisa em enfermagem. 3a ed. Porto Alegre: Artes M édicas; 1995.

18. Bardin L. Análise de conteúdo. Lisboa: Edições 70; 1995.

19. Brasil. M inistério da Saúde. Conselho Nacional de Saúde. Comissão Nacional de Ética em Pesquisa CONEP. Resolução no 196/96. Dispõe sobre pesquisa envolvendo seres humanos. Diário Oficial da União 1996; 16 out.

20. Chiavenato I. Gerenciando pessoas: o passo decisivo para a administração participativa. $2^{\underline{a}}$ ed. São Paulo: Makron Books; 1994

21. Pierantoni CR, Varella TC, França T. Recursos Humanos e gestão do Trabalho em Saúde: da teoria para a prática. 2004. [acessado 2006 jun 24]. Disponível em: http://www.opas.org.br

22. Lazzarotto EM . Competências essenciais requeridas para o gerenciamento de unidades básicas de saúde [dissertação]. Florianópolis (SC): Universidade Federal de Santa Catarina; 2001. 
23. Shimizu HE, Santos ER. Percepção de Gerentes sobre a Assistência à Saúde Coletiva. Revista Bras. Enferm. 2002; 55(2):157-162.

24. Brasil. Conselho Nacional de Secretários de Saúde. Para entender a gestão do SUS/Conselho Nacional de Secretários de Saúde. Brasília: CONASS; 2003.

25. Teixeira CF, Molesini JA. Gestão Municipal do SUS: atribuições e responsabilidades do gestor do sistema e dos gerentes de unidades de saúde. Revista Baiana de Saúde Pública 2002; 26(1/2):29-40.

26. Quinn RE, Thompson $M$, Faerman SR, McGrath $M$. Competências gerenciais: princípios e aplicações. Rio de Janeiro: Elsevier; 2003.

27. Fraccolli LA, Maeda ST. A gerência nos serviços públicos de saúde: um relato de experiência. Escola Enfermagem USP 2000; 34(2):213-217.

28. Ferreira AS. Competências gerenciais para unidades básicas do Sistema Único de Saúde. Cien Saude Colet 2004; 9(1):69-76.

29. M erhy EL. $O$ ato de governar as tensões constitutivas do agir em saúde como desafio permanente de algumas estratégias gerenciais. Cien Saude Colet 1999; 4(2):305-314.

30. Rossi FR, Silva MAD. Fundamentos para processos gerenciais na prática do cuidado. Escola Enfermagem USP 2005; 39(4):460-468.

31. Freitas FP, Pinto IC. Percepção da Equipe de Saúde da Família sobre a utilização do Sistema de Informação da Atenção Básica-SIAB. Rev Latino-am enfermagem 2005; 13(4):547-554.

32. Arrethe M. Financiamento federal e gestão local de políticas sociais: o difícil equilíbrio entre regulação, responsabilidade e autonomia. Cien Saude Colet 2003; 8(2):331-345.

33. Kurcgant P. Gerenciamento em enfermagem. Rio de Janeiro: Guanabara Koogan; 2005.

34. Senac DN. Habilidades gerenciais. Rio de Janeiro: SENAC Nacional; 1997.

35. Pinheiro DPN. A resiliência em discussão. Psicologia em estudo 2004; 9(1):67-75.

36. Santos MJN. Gestão de recursos humanos: teorias e práticas. Sociologias 2004; 6(12): 142-158.

Artigo apresentado em 19/07/2007

Aprovado em 13/12/2007 